\title{
PREPARATION OF GRAPHITE TARGETS FROM SMALL MARINE SAMPLES FOR AMS RADIOCARBON MEASUREMENTS
}

\author{
Laval Liong Wee Kwong ${ }^{1}$ Pavel P Povinec ${ }^{1,2} \bullet$ A J Timothy Jull ${ }^{3}$
}

\begin{abstract}
A vacuum sample processing line was set up and methods were developed for the determination of radiocarbon in small-volume seawater and biota samples. Seawater samples $(500 \mathrm{~mL}$ per borosilicate glass bottle and poisoned with $\mathrm{HgCl}_{2}$ ) were acidified with $5 \mathrm{~mL}$ concentrated hydrochloric acid. Pure $\mathrm{N}_{2}$ was used as a carrier gas to strip $\mathrm{CO}_{2}$ from the samples for $10 \mathrm{~min}$ in a circulation mode. After purification through several water traps, the $\mathrm{CO}_{2}$ was isolated cryogenically. Using $\mathrm{Na}_{2} \mathrm{CO}_{3}$ standard solutions, recovery yields were calculated superior to $95 \pm 5 \%$. Freeze-dried marine biota samples were thoroughly mixed with $\mathrm{Cu}(\mathrm{II}) \mathrm{O}$ and combusted at $900{ }^{\circ} \mathrm{C}$. The $\mathrm{CO}_{2}$ was purified by passing through $\mathrm{Ag}$ wool and $\mathrm{Cu}$ granules at $450^{\circ} \mathrm{C}$ before reduction to graphite. Finally, graphite was synthesized using $\mathrm{Zn}$ dust heated to $450{ }^{\circ} \mathrm{C}$ in the presence of an $\mathrm{Fe}$ catalyst at $550^{\circ} \mathrm{C}$. Although this method takes about $8 \mathrm{hr}$ (synthesis done overnight), the advantage is that no water vapor by-product is formed to hinder the reaction. The graphite yields, measured both by gravimetric methods and by pressure readings, were $95 \pm 5 \%$. Accelerator mass spectrometry (AMS) measurements were carried out at the NSF-Arizona AMS Facility. Results for water samples from the northwest Pacific Ocean are reported which are in agreement with data reported elsewhere.
\end{abstract}

\section{INTRODUCTION}

Due to its ubiquitous nature and relatively long half-life (5730 yr), radiocarbon is a unique tracer which has been applied in a wide range of disciplines including marine sciences. ${ }^{14} \mathrm{C}$ is a useful tool for studying the ocean carbon cycle, oceanic transport, water mass circulation, and mixing processes (e.g. Östlund and Stuiver 1980; Stuiver et al. 1983; Östlund et al. 1987; Bard et al. 1989; Östlund and Rooth 1990; Broecker et al. 1998; Lawson et al. 2000; Povinec et al. 2000; Aramaki et al. 2001; Key et al. 2002, etc.).

The 2 approaches for ${ }^{14} \mathrm{C}$ determination are conventional radiometrics $\beta$-counting and accelerator mass spectrometry (AMS) techniques. In the first method, $\mathrm{CO}_{2}$ is generated from the sample, purified or converted to a hydrocarbon gas, and then analyzed by a gas proportional counter (e.g. Povinec 1992; Povinec 1994; Gorczyca et al. 1998, etc.). Alternatively, carbon dioxide can be converted to benzene, which is analyzed by liquid scintillation counting (e.g. Calf 1978; Burchuladze et al. 1980, etc.). Although the 2 methods have been intensively used, they have proved to be limited when dealing with small sample sizes and low ${ }^{14} \mathrm{C}$ levels, like, for example, in dissolved inorganic carbon (DIC) measurements in seawater for high-resolution $\Delta^{14} \mathrm{C}$ profiling of the water column. As ${ }^{14} \mathrm{C}$ has a very low natural abundance and a slow decay rate, either a very long counting time is necessary or very large quantities of samples are required for good precision measurements. For example, when measuring DIC in seawater, large volumes of the order of 250-300 L are required (Bhushan et al. 1994). In polar regions, which are key areas for deep-water circulation studies, or when deep-water samples are needed for specific analyses, it is very difficult and time consuming to collect large-volume samples. A typical chemical procedure involves precipitation as $\mathrm{Na}_{2} \mathrm{CO}_{3}$ or $\mathrm{BaCO}_{3}$, usually done on shipboard immediately after sampling. In the home laboratory, $\mathrm{CO}_{2}$ is generated and counted in a gas proportional counter, or acetylene is produced and benzene is obtained by cyclotrimerization of acetylene before liquid scintillation counting (e.g. Calf 1978; Burchuladze et al. 1980; Bhushan et al. 1994, etc.).

\footnotetext{
${ }^{1}$ International Atomic Energy Agency, Marine Environment Laboratory, MC 98000 Monaco.

${ }^{2}$ Corresponding author. Email address: p.povinec@iaea.org.

${ }^{3}$ NSF Arizona AMS Facility, The University of Arizona, Tucson, Arizona 85721, USA.
}

(C) 2004 by the Arizona Board of Regents on behalf of the University of Arizona Proceedings of the 18th International Radiocarbon Conference, edited by N Beavan Athfield and R J Sparks RADIOCARBON, Vol 46, Nr 1, 2004, p 133-139 
An alternative approach to decay counting is to measure the number of ${ }^{14} \mathrm{C}$ atoms in a sample, more precisely, the ratio of ${ }^{14} \mathrm{C}$ atoms to the stable carbon isotope atoms by AMS. With a state-of-the-art AMS technique, a sub-mg level of graphite suffices; consequently, a volume of $500 \mathrm{~mL}$ is enough for processing seawater samples. The major steps involved are $\mathrm{CO}_{2}$ extraction and reduction. For seawater, the extraction is performed by first hydrolyzing the seawater and then stripping $\mathrm{CO}_{2}$ either by bubbling with a carrier gas (e.g. Östlund et al. 1987) or by vacuum extraction (e.g. Dörr and Munnich 1980; Nydal et al. 1992; McNichol et al. 1994). For marine biota, the sample is either combusted with an oxidant at $900{ }^{\circ} \mathrm{C}$, or, if in the form of a calcareous solid like a shell or coral, the sample can be wet-digested with phosphoric acid. The reduction to filamentous graphite is carried out using $\mathrm{H}_{2}$ in the presence of $\mathrm{Fe}$ metal activated by $\mathrm{O}_{2}$ (e.g. Vogel et al. 1984). However, an elaborate installation is required involving a heater and a water trap to eliminate the $\mathrm{H}_{2} \mathrm{O}$ byproduct which kills reduction. $\mathrm{Zn}$ has also been used as a reducing agent in the presence of a metal catalyst such as Fe (Jull et al. 1987). Here, the reaction usually lasts several hours. The graphite is then pressed as a target for AMS measurements.

To carry out ${ }^{14} \mathrm{C}$ assessment of small volume marine samples, a vacuum sample preparation line was constructed at the International Atomic Energy Agency's Marine Environment Laboratory (IAEAMEL) in Monaco, and methods were developed to produce graphite targets for marine environmental studies. The adopted procedures are briefly described in the present paper.

\section{METHODS}

Seawater samples were collected in precleaned (rinsed several times with hexane and dried overnight in an oven at $100{ }^{\circ} \mathrm{C}$ ), preweighed $500-\mathrm{mL}$ borosilicate glass bottles and poisoned immediately with $\mathrm{HgCl}_{2}$ (McNichol and Jones 1992). To minimize contamination, $\mathrm{CO}_{2}$ was stripped in the bottles in which the seawater was collected. Biota samples were frozen before being lyophilized and ground into a fine homogeneous powder.

\section{Extraction of $\mathrm{CO}_{2}$}

\section{Seawater}

In a glove box under a high-purity $\mathrm{N}_{2}$ atmosphere, a stripping probe was inserted into the sample bottle and a glassware assembly was set up which was connected to the preparation line (Figure 1). Then a vacuum was generated up to the glassware assembly's valves. Standard water traps at $-80{ }^{\circ} \mathrm{C}$, a slurry of ethanol and dry ice, and a liquid $\mathrm{N}_{2}$ bath were installed before the seawater was hydrolyzed with $5 \mathrm{~mL}$ of concentrated $\mathrm{HCl}$. High-purity carrier $\mathrm{N}_{2}$ gas was injected into the line until a pressure of $0.1 \mathrm{MPa}$ was reached. Immediately, the appropriate valves were opened to create a circulation loop, and a bellows pump (Iwaki ${ }^{\circledR} \mathrm{BA}-110 \mathrm{SN}$ ) was switched on, forcing the carrier gas through the fritted end of the probe. The seawater sample is thus sparged along by the $\mathrm{N}_{2}$ gas carrying $\mathrm{CO}_{2}$ to be trapped. This stripping process was completed in $10 \mathrm{~min}$. The carrier and other non-condensable gas was then purged out. While the trapped $\mathrm{CO}_{2}$ was allowed to thaw, the liquid $\mathrm{N}_{2}$ bath was replaced by a water bath cooled to $-80^{\circ} \mathrm{C}$. After equilibrium was reached, the $\mathrm{CO}_{2}$ was cryogenically transferred to the calibrated volume section to which a high-precision pressure transducer was connected. The measured pressure was used to calculate the concentration of the extracted $\mathrm{CO}_{2}$. The calibrated volume section was also used to collect precisely known amounts of $\mathrm{CO}_{2}$ for graphite synthesis and measurement of ${ }^{13} \mathrm{C}$. 


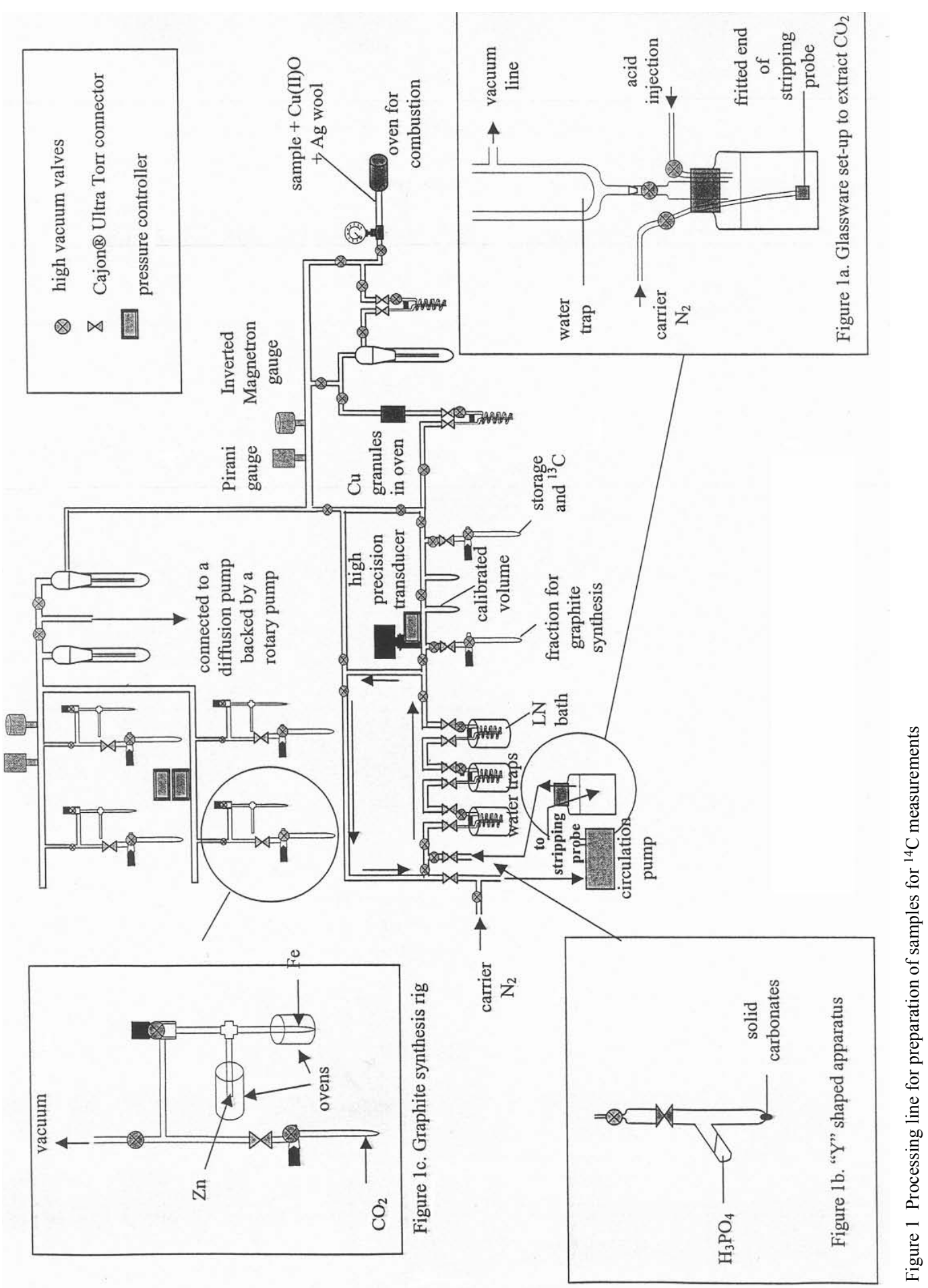


Biota

Fifty $\mathrm{mg}$ of freeze-dried marine biota sample was thoroughly mixed with $1000 \mathrm{mg}$ of $\mathrm{Cu}(\mathrm{II}) \mathrm{O}$ and combusted under vacuum at $900{ }^{\circ} \mathrm{C}$ in a $9-\mathrm{mm}$ Vycor ${ }^{\circledR}$ tube connected to the processing line. For samples of suspected higher activity, the mixture was flame-sealed in the tube before combustion in a separate oven to avoid contaminating the line. The $\mathrm{CO}_{2}$ was purified by passing the produced gas through pure $\mathrm{Ag}$ wool, water traps cooled at $-80{ }^{\circ} \mathrm{C}$, and a column of packed $\mathrm{Cu}$ granules at $450{ }^{\circ} \mathrm{C}$. An aliquot of the pure $\mathrm{CO}_{2}$ of precisely known volume was reduced to graphite while a second fraction was used for $\delta^{13} \mathrm{C}$ determination.

When dealing with solid samples like shells and corals, small pieces of the material are introduced into one of the arms of the extraction glassware apparatus for solid samples depicted in Figure $1 \mathrm{~b}$. Five $\mathrm{mL}$ of $\mathrm{H}_{3} \mathrm{PO}_{4}$ was carefully introduced into the side arm before connecting the apparatus to the line and generating a vacuum. The extraction apparatus was then isolated from the processing line by means of 2 valves, enabling its disconnection from the line. No leakage was observed during this manipulation. The acid was gently tipped over the solid sample, thus liberating $\mathrm{CO}_{2}$. For complete dissolution, gentle heating was sometimes necessary. After total digestion, the extraction apparatus was again connected to the line and the $\mathrm{CO}_{2}$ was purified as previously described before graphite synthesis and $\delta^{13} \mathrm{C}$ measurement.

\section{Reduction of $\mathrm{CO}_{2}$}

The reduction was carried out with $\mathrm{Zn}$ in the presence of dendritic Fe (200 mesh) (Slota et al. 1987). Both chemicals were carefully weighed and introduced into 6-mm-diameter Vycor tubes. They were then connected to the graphite apparatus, together with a tube filled with purified (using liquid nitrogen and dry ice traps) $\mathrm{CO}_{2}$ extracted from a sample, as shown in Figure 1c. The air above was carefully pumped out and the $\mathrm{CO}_{2}$ transferred cryogenically to the reactor. The $\mathrm{Zn}$ tube was then heated to $450{ }^{\circ} \mathrm{C}$, which pre-reduced $\mathrm{CO}_{2}$ to $\mathrm{CO}$. After $1 \mathrm{hr}$, the $\mathrm{Fe}$ was heated to $550{ }^{\circ} \mathrm{C}$ and graphite was produced and deposited onto the $\mathrm{Fe}$. The pressure was constantly monitored until the reaction was completed, which usually takes between 8 to $10 \mathrm{hr}$, by means of a transducer connected to a computer via a data acquisition system. The product was then weighed very carefully. The graphite yield was calculated both gravimetrically and manometrically from pressure readings.

For a 6-mm-diameter tube, $2 \mathrm{mg}$ of carbon was found to be the appropriate amount for synthesis. The mass of Fe used, enabling to reach an acceptable ionic current in the AMS source, was twice the amount of carbon that needed to be reduced. For complete reduction, the pressure should drop to zero, meaning all gaseous $\mathrm{CO}_{2}$ and $\mathrm{CO}$ has been reduced to solid graphite. The reactions occurring within the reactor are the following:

$$
\begin{gathered}
\mathrm{CO}_{2}+\mathrm{Zn} \stackrel{450^{\circ} \mathrm{C}}{\rightarrow} \mathrm{CO}+\mathrm{ZnO} \\
2 \mathrm{CO} \stackrel{550^{\circ} \mathrm{C}}{\rightarrow} \mathrm{CO}^{2}+\mathrm{C} \text { (graphite). }
\end{gathered}
$$

Figure 2 shows the variation of pressure with time. Curve 2 shows successful synthesis with a yield of about $98 \%$. Curve 1 shows a synthesis with a yield of about $95 \%$, as the curve did not return to a zero pressure state, probably because of the presence of water vapors in the system. Curves 3 and 4 are examples where no synthesis took place at all. The constant increase in pressure with time in curve 4 is an indication of a leakage in the graphite apparatus (probably due to a damaged O-ring). In reaction 5, the synthesis seemed to end prematurely at point $\mathrm{A}$, which would have resulted in a poor graphite yield and probable isotopic fractionation. However, on removing the tube furnace, a 
yellow deposit was noticed on the $\mathrm{Zn}$ surface. It was concluded that it was sulphur, obtained by the reduction of co-extracted $\mathrm{SO}_{2}$, which was hindering the graphite synthesis. By gently tapping the $\mathrm{Zn}$ tube with a spatula and re-setting the furnaces, the reaction continued to completion as depicted.

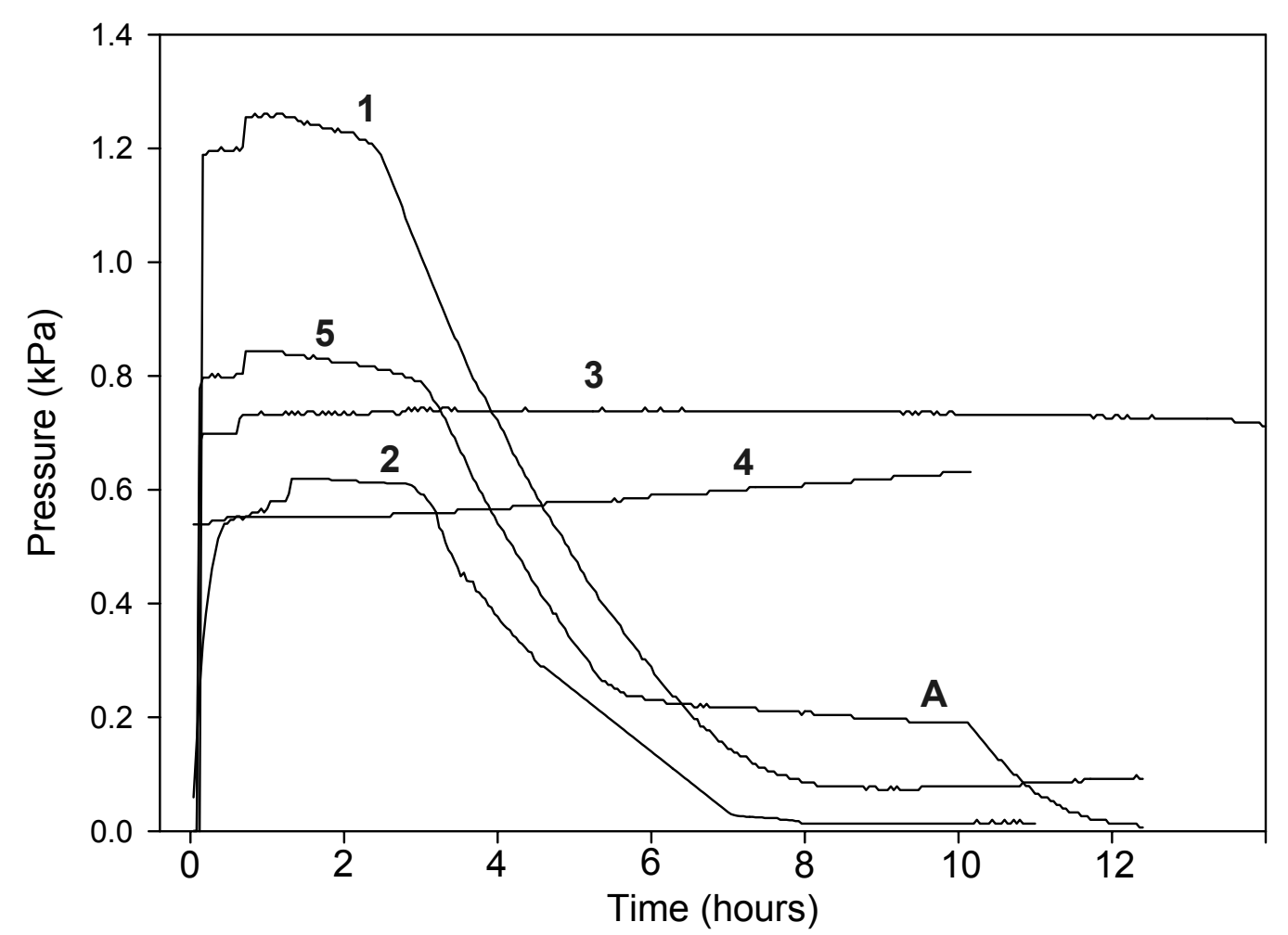

Figure 2 Variation of pressure during the graphite synthesis

\section{RESULTS AND DISCUSSION}

To verify that the $\mathrm{CO}_{2}$ extraction procedure from water samples was quantitative, known amounts of $\mathrm{Na}_{2} \mathrm{CO}_{3}$ standards, which were dried overnight at $200{ }^{\circ} \mathrm{C}$ in an oven, were dissolved in degassed Milli- $Q^{\circledR}$ water. As soon as the dissolution was complete, the solution was processed. The mean recovery yield for 5 extractions was $95 \pm 5 \%$. Similarly, to check the performance of the wet-digestion procedure, exactly known amounts of solid $\mathrm{Na}_{2} \mathrm{CO}_{3}$ were hydrolyzed with $\mathrm{H}_{3} \mathrm{PO}_{4}$ using the extraction apparatus for solid samples as described above. The mean recovery was $97 \pm 3 \%$ for 5 extractions.

The combustion procedure was tested by burning $50 \mathrm{mg}$ of the National Institute of Standards and Technology's (Gaithersburg, USA) oxalic-acid standard reference material (HOxII, NIST SRM 4990C) with an excess of $\mathrm{Cu}(\mathrm{II}) \mathrm{O}$. The compounds were thoroughly mixed in a 9-mm-diameter Vycor tube and combusted at $900{ }^{\circ} \mathrm{C}$ under vacuum. Aliquots of $4 \mathrm{~mL}$ (STP) of pure $\mathrm{CO}_{2}$ were taken for the measurement of ${ }^{13} \mathrm{C}$. In addition, other aliquots of $\mathrm{CO}_{2}$ were reduced to graphite. These were then strongly heated with a torch, so that the graphite would oxidize back to $\mathrm{CO}_{2}$. New $\delta^{13} \mathrm{C}$ values were again measured and they agreed with the initial ${ }^{13} \mathrm{C}$ values, proving the validity of the procedure. All stable isotope analyses were within $0.3 \%$. The reproducibility of ${ }^{14} \mathrm{C}$ measurements on the 
NIST standard reference material was better than $15 \%$. All graphite samples discussed in this paper were analyzed by the AMS facility of the University of Arizona.

Finally, several replicate samples of seawater were collected in the Mediterranean near the port of Monaco, and processed according to the performance check tests described above. The mean concentration of $\mathrm{CO}_{2}$ extracted was $2.64 \pm 0.18 \mathrm{mmol} \mathrm{kg}{ }^{-1}$. The $\delta^{13} \mathrm{C}$ values ranged from -0.80 to $-1.18 \%$ and $\Delta^{14} \mathrm{C}$ values were in the interval of $70-80 \%$. For testing purposes, seawater samples collected at Station $1\left(34^{\circ} 59^{\prime} \mathrm{N}, 145^{\circ} 59^{\prime} \mathrm{E}\right)$ of the IAEA 1997 Pacific Ocean expedition were also processed according to the developed procedure. The $\Delta^{14} \mathrm{C}$ profile is shown in Figure 3 and corroborates well with results published by Aramaki et al. (2001).

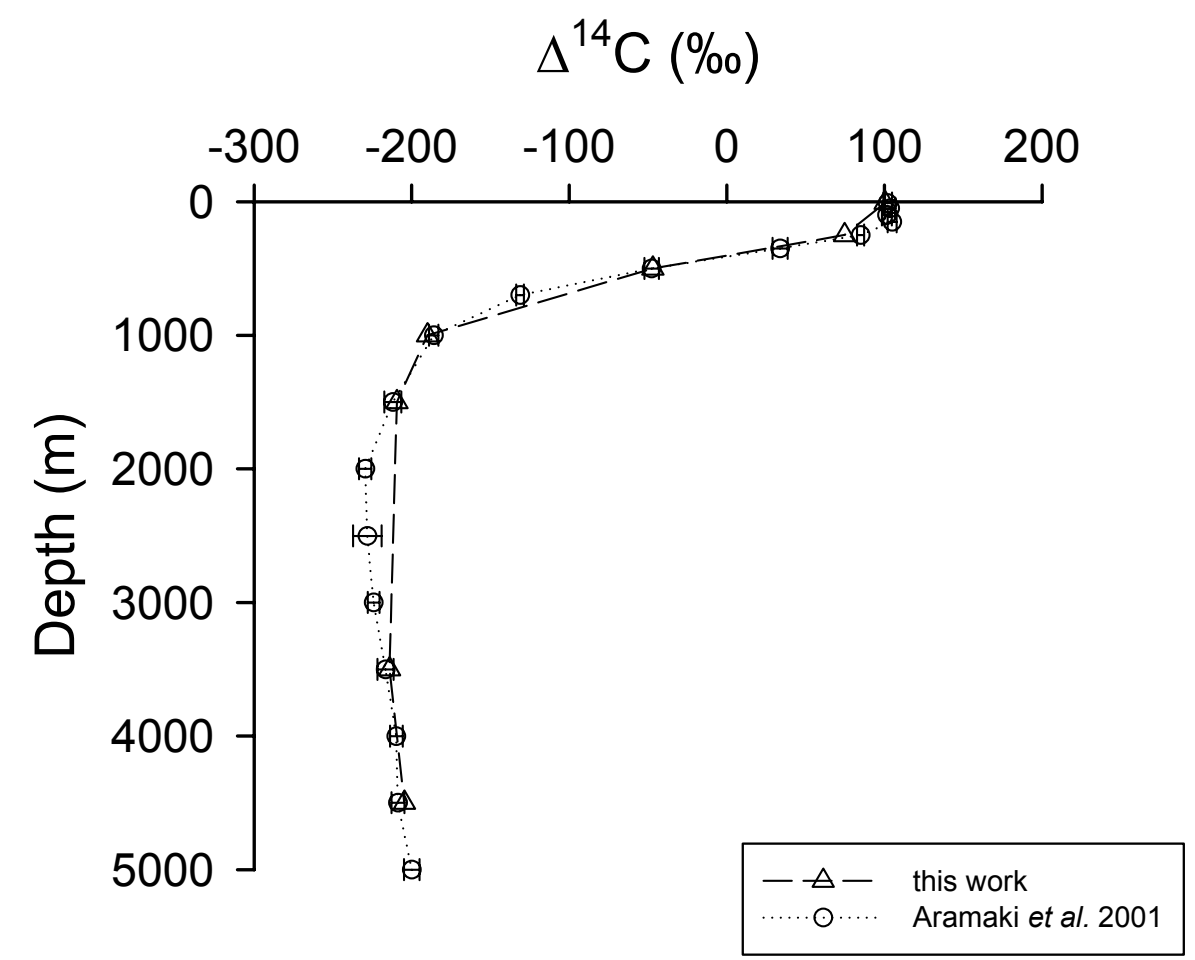

Figure $3 \Delta{ }^{14} \mathrm{C}(\%)$ profile for Station 1 of the IAEA 1997 Pacific Ocean expedition (this work and Aramaki et al. 2001).

Analyses of marine biota samples (plankton, fish, and corals) have been carried out for carbon flux studies and investigations of transport and exchange processes between seawater and marine biota. The obtained results will be published in a separate paper.

\section{CONCLUSIONS}

Development of the ${ }^{14} \mathrm{C}$ line at the IAEA's Marine Environment Laboratory in Monaco and the sample processing procedures have proved to be successful, giving results comparable to published values. For routine water analyses, a rigorous internal verification procedure has been implemented and is carried out on a continuous basis. Each set of samples is processed together with $\mathrm{Na}_{2} \mathrm{CO}_{3}$ standards and another seawater sample of known concentration (a water sample collected off the port of Monaco,) which is used as an internal reference material. Measurements of ${ }^{14} \mathrm{C}$ in seawater 
and marine biota such as plankton will continue to be carried out for investigations of processes in the water column, climate change and carbon flux studies, and investigations of transport and exchange processes between seawater and marine biota.

\section{ACKNOWLEDGEMENTS}

The authors are indebted to Mr T Lange of the University of Arizona's AMS Facility for the installation of the sample processing line and his advice. IAEA-MEL operates under a bilateral agreement between the International Atomic Energy Agency and the Government of the Principality of Monaco.

\section{REFERENCES}

Aramaki T, Mizushima T, Kuji T, Povinec PP, Togawa O. 2001. Distribution of radiocarbon in the southwestern North Pacific. Radiocarbon 43(2B):857-67.

Bard E, Arnold M, Toggweiler JR, Maurice P, Duplessy J-C. 1989 . Bomb ${ }^{14} \mathrm{C}$ in the Indian Ocean measured by accelerator mass spectrometry: oceanographic implications. Radiocarbon 31(3):510-22.

Broecker WS, Peacock SL, Walker S, Weiss R, Fahrbach E, Schroeder M, Mikolajewicz U, Heinze C, Key R, Peng TH, Rubin S. 1998. How much deep water is formed in the Southern Ocean. Journal of Geophysical Research 103:15,833-44.

Burchuladze AA, Pagava SV, Povinec PP, Togonoidze GI, Usacev S. 1980. Radiocarbon variations with the 11-year solar cycle during the last century. Nature 287:320-2.

Bushan R, Chakraborty S, Krishnaswami S. 1994. Physical Research Laboratory (Chemistry) radiocarbon date list 1. Radiocarbon 36(2):251-6.

Calf GE. 1978. A procedure for the preparation of benzene from ${ }^{14} \mathrm{C}$ NBS oxalic acid standard. Radiocarbon 20(2):169-170.

Dörr H, Munnich KO. 1980. Carbon-14 and carbon-13 in soil CO. Radiocarbon 22(3):909-18.

Gorczyca Z, Jelen K, Kuc T. 1998. Gas counting system for ${ }^{14} \mathrm{C}$ dating of small samples in the Krakow Laboratory. Radiocarbon 40(1):129-36.

Jull AJT, Linick TW, Toolin LJ. 1987. Preparation of small samples for ${ }^{14} \mathrm{C}$ accelerator targets by catalytic reduction of CO. Radiocarbon 29(2):303-6.

Key RM, Quay PD, Schlosser P, McNichol AP, von Reden KF, Schneider RJ, Elder KL, Stuiver M, Östlund HG. 2002. WOCE Radiocarbon IV: Pacific Ocean results; P10, P13N, P14C, P18, P19 \& S4P. Radiocarbon 44(1):239-392.

Lawson E, Elliott G, Fallon J, Fink D, Hotchkis MAC, Hua Q, Jacobsen G, Lee P, Smith AM, Tuniz C, Zoppi U. 2000. AMS at ANTARES-the first 10 years. Nuclear Instruments and Methods in Physics Re- search $B$ 172:95-9.

McNichol AP, Jones GA, Hutton, DL, Gagnon AR. 1994. The rapid preparation of seawater $\Sigma \mathrm{CO}_{2}$ for radiocarbon analysis at the National Ocean Sciences AMS Facility. Radiocarbon 36(2):237-46.

Nydal R, Giselfoss J, Skjelvan I, Skogseth F. 1992. ${ }^{14} \mathrm{C}$ profiles in the Norwegian and Greenland Seas by conventional and AMS measurements. Radiocarbon 34(3):717-26.

Östlund HG, Stuiver M. 1980. GEOSECS Pacific radiocarbon. Radiocarbon 22(1):25-53.

Östlund HG, Craig H, Broecker WS, Spenser D. 1987. GEOSECS Atlantic, Pacific and Indian Ocean Expeditions. Vol. 7. Shorebased Data and Graphics. Washington, DC: National Science Foundation.

Östlund HG, Rooth CGH. 1990. The North Atlantic tritium and radiocarbon transients 1972-1983. Journal of Geophysical Research 95(C11):20,147-65.

Povinec PP. 1992. ${ }^{14} \mathrm{C}$ gas counting: Is there still a future? Radiocarbon 34(3):406-13.

Povinec PP. 1994. Underground low-level counting. In: Proceedings of the 3rd International Conference on Low-level Measurements of Radioactivity in the Environment. Singapore: World Scientific. p 113-39.

Povinec PP, Oregioni B, Jull AJT, Kieser WE, Zhao X-L. 2000. AMS measurements of ${ }^{14} \mathrm{C}$ and ${ }^{129} \mathrm{I}$ in seawater around radioactive waste dump sites. Nuclear Instruments and Methods in Physics Research B 172:672-8.

Slota PJ, Jull AJT, Linick TW, Toolin LJ. 1987. Preparation of small samples for ${ }^{14} \mathrm{C}$ accelerator targets by catalytic reduction of $\mathrm{CO}_{2}$. Radiocarbon 29(2):303.

Stuiver M, Quay PD, Östlund HG. 1983. Abyssal water carbon-14 distribution and the age of the world oceans. Science 219:849.

Vogel JS, Southon JR, Nelson DE, Brown TA. 1984. Performance of catalytically condensed carbon for use in accelerator mass spectrometry. Nuclear Instruments and Methods in Physics Research B 5:289-93. 